\title{
Comparison of polymers to enhance mechanical properties of microneedles for bio-medical applications
}

\author{
Gwenaël Bonfante ${ }^{1 *}$, Hakjae Lee², Leilei Bao², Jongho Park², Nobuyuki Takama² and Beomjoon Kim² (1)
}

\begin{abstract}
To pierce through the skin and interact with the first biofluid available, microneedles should be mechanically strong. However, some polymers used to fabricate microneedles yield insufficient strength for the fabrication of arrays (PDMS, highly porous structures, etc.). To enhance mechanical properties, piercing materials can be used. They aim to pierce the skin evenly and dissolve quickly, clearing the way for underlying microneedles to interact with the interstitial fluid (ISF). Three materials — carboxymethyl cellulose (CMC), alginate, and hyaluronic acid (HA) — are discussed in this article. Low concentrations, for a quick dissolution while keeping enhancing effect, are used ranging from 1-5\%(w/w) in deionized water. Their overall aspects, such as geometrical parameters (tip width, height, and width), piercing capabilities, and dissolution time, are measured and discussed. For breaking the skin barrier, two key parameters-a sharp tip and overall mechanical strength — are highlighted. Each material fails the piercing test at a concentration of $1 \%(\mathrm{w} / \mathrm{w})$. Concentrations of $3 \%(\mathrm{w} / \mathrm{W})$ and of $5 \%(\mathrm{w} / \mathrm{w})$ are giving strong arrays able to pierce the skin. For the purpose of this study, $\mathrm{HA}$ at a concentration of $3 \%(\mathrm{w} / \mathrm{w})$ results in arrays composed of microneedles with a tip width of $48 \pm 8 \mu \mathrm{m}$ and pierced through the foil with a dissolution time of less than $2 \mathrm{~min}$.
\end{abstract}

Keywords: Microneedles, Piercing materials, Enhancing materials, Drug delivery, Carboxymethyl cellulose, Alginate, Hyaluronic acid

\section{Introduction}

In a constantly evolving world, due to the increasing medical efficiency and accessibility demands, the fabrication and optimization of simpler, less invasive and safer devices have to be asserted. For example, standard glucose monitoring devices require blood for their measurement, and the blood is obtained by repetitively pricking the subject's finger throughout the day; as a broader view, drug delivery technologies require specific packaging (smart drug delivery, etc.) as well as trained medical personnel (vaccine administration, etc.). In addition, most biomarker sensing devices require blood for analyses; for this purpose,

*Correspondence: gwenbonf@iis.u-tokyo.ac.jp

1 LIMMS/CNRS-IIS UMI 2820, The University of Tokyo, Tokyo, Japan

Full list of author information is available at the end of the article the dermis needs to be pierced to reach the blood vessel and nerves. However, the interstitial fluid (ISF) is a biofluid that can be accessed without causing pain to the subject: ISF is located above pain receptors. ISF is abundantly available among all bodily fluids, unlike sweat, urine, or tears, which are linked to bodily responses. Moreover, its composition proportional to blood make it a good candidate for continuous monitoring of biomarker as well as its accessibility for localized drug delivery [1-3]. To reach ISF, hypodermal needles can be superfluous, i.e. being too dangerous, invasive, requiring trained medical staff, heavy waste management, thus generating anxiety and pain [4-7]. For this purpose, an array of microneedles has been investigated in recent researches. These microneedles can access ISF by causing minimum pain and invasiveness [8-12]. Different microneedles serve different 
purposes, and the four main types of them include plain, hollow, coated and dissolvable [13-17]. Plain microneedles permit to open the way by poking a hole in the skin for a better penetration of medicine [18]; hollow microneedles are used for bio-sensing and drug delivery [19-21]; coated microneedles are mainly used for drug delivery [22], and finally, dissolvable microneedles can serve for both bio sensing and drug delivery purposes [23, 24]. Among the microneedle's category cited previously, dissolvable microneedles which are made of biodegradable and bio-compatible polymers meet all the required specifications of a new generation of ISF interacting devices. Specific morphology like highly porous or sponge like (PDMS) microneedles can be used for interacting with ISF $[9$, 25]. Drug delivery as well as sensing efficiency relies on robust mechanical properties, piercing capabilities, and dissolution time. In highly porous material or sponge like material, lack of strength is intrinsically linked to their morphology [26]. Naturally, extremely high porosity must be attained to interact with ISF, further leading to a decrease in the overall mechanical properties. To assert this issue, different enhancing materials can be used. Porous microneedles can be topped with these materials; such material permits the needles to break through the skin, thereby enabling access to the ISF. They must be sufficiently strong to evenly pierce the skin, while maintaining their sharpness, as well as dissolving rapidly after entering the body. The main goal of this article is to help underlying microneedle to have sufficient strength to pierce the skin without interfering with their desired application. For this purpose, three materials such as hyaluronic acid (HA), carboxymethyl cellulose (CMC) and alginate $[24,27-31]$, that are widely used in biomedical field, were studied. These materials are approved by the United States Food and Drug Administration (FDA) as well as bio compatible and biodegradable materials [32-34]. This article discusses the comparison of these three materials by considering their overall aspects, such as geometrical parameters after molding and thermal annealing, piercing capabilities, and dissolution time, to find the most suitable material for microneedle technology. To rapidly dissolve, and not interfere with the desired application, the less possible material should be used; thus, low concentrations are used at 1,3 and $5 \%(\mathrm{w} / \mathrm{w})$. These concentrations are considered low regarding the use of $\mathrm{HA}, \mathrm{CMC}$ and alginate as the main material for fabricating microneedles [27, 30, 35]. Indeed, if too much material is used, clogging of the underlying microneedle can occur, nullifying the aimed application such as drug delivery and bio sensing.

\section{Materials and methods}

\section{Materials}

HA has been provided by RAPHAS Co. Ltd., Korea. Sodium CMC was obtained from Merck Japan (Sigma Aldrich). Sodium alginate sample has been kindly offered by KIMICA Corporation, Japan. Polydimethylsiloxane (PDMS) (SILPOT ${ }^{\mathrm{TM}}$ 184) was obtained from Dow Corning Corp., Japan. Agarose gel was made from Fast Gene NE-AG01 agarose powder. All chemicals were used as delivered.

\section{Fabrication of arrays}

The arrays were fabricated via micro-molding method. A female PDMS mold was fabricated by casting PDMS on a metal master mold and after annealing at $80{ }^{\circ} \mathrm{C}$ for $1 \mathrm{~h}$; this master mold was designed using an array comprising 169 microneedles with a height of approximately $1200 \mu \mathrm{m}$ and bottom width of approximately $600 \mu \mathrm{m}$ (Fig. 1). The master mold was fabricated by electro-discharge machining. The microneedles were in the shape of a square based pyramid with a total volume of $850 \mu \mathrm{L}$. For preparing the PDMS mold, a resin base and curing agent were mixed in the ratio of 10:1. The metal mold was placed in the mixture, degassed under vacuum at around $1 \mathrm{kPa}$, and annealed at $80^{\circ} \mathrm{C}$ for $1 \mathrm{~h}$ in an oven. The resulting mold was peeled and used as it is.

In order to prepare solutions of different concentrations for each material, the required amount of material was dissolved in de-ionized water $(1,3$, and 5 in $\%(w / w)$ ratios) and vigorously agitated at $1000 \mathrm{rpm}$ using a stirring magnet. For $\mathrm{CMC}$ and alginate, they required $2 \mathrm{~h}$ for homogeneous solution as the dissolution was difficult. Thus, heating the solution $\left(40^{\circ} \mathrm{C}\right)$ gently was performed to help dissolution of the material. The solution of the material to be cast was poured into the mold, placed in a vacuum box for degassing at $1 \mathrm{kPa}$, and then annealed at $60{ }^{\circ} \mathrm{C}$ for $2 \mathrm{~h}$, until the array was completely dried.

\section{Methods}

Overall geometry and other aspects were measured using a 3D digital fine microscope (VC-3000, Omron Co., Japan). The height, width, and tip width were measured and compared. A total of 50 distinct microneedles were measured within five distinct arrays for each material with different concentrations in order to be statistically representative of each concentration for each material.

It is essential that the piercing properties are even throughout the array. Uneven pressure can lead to defect while testing, inserting uncontrollable and unwanted parameters in the measurement. However, apply the same pressure at every point of the array while measuring the piercing properties is difficult. Therefore, a press composed of two jaws was used for 


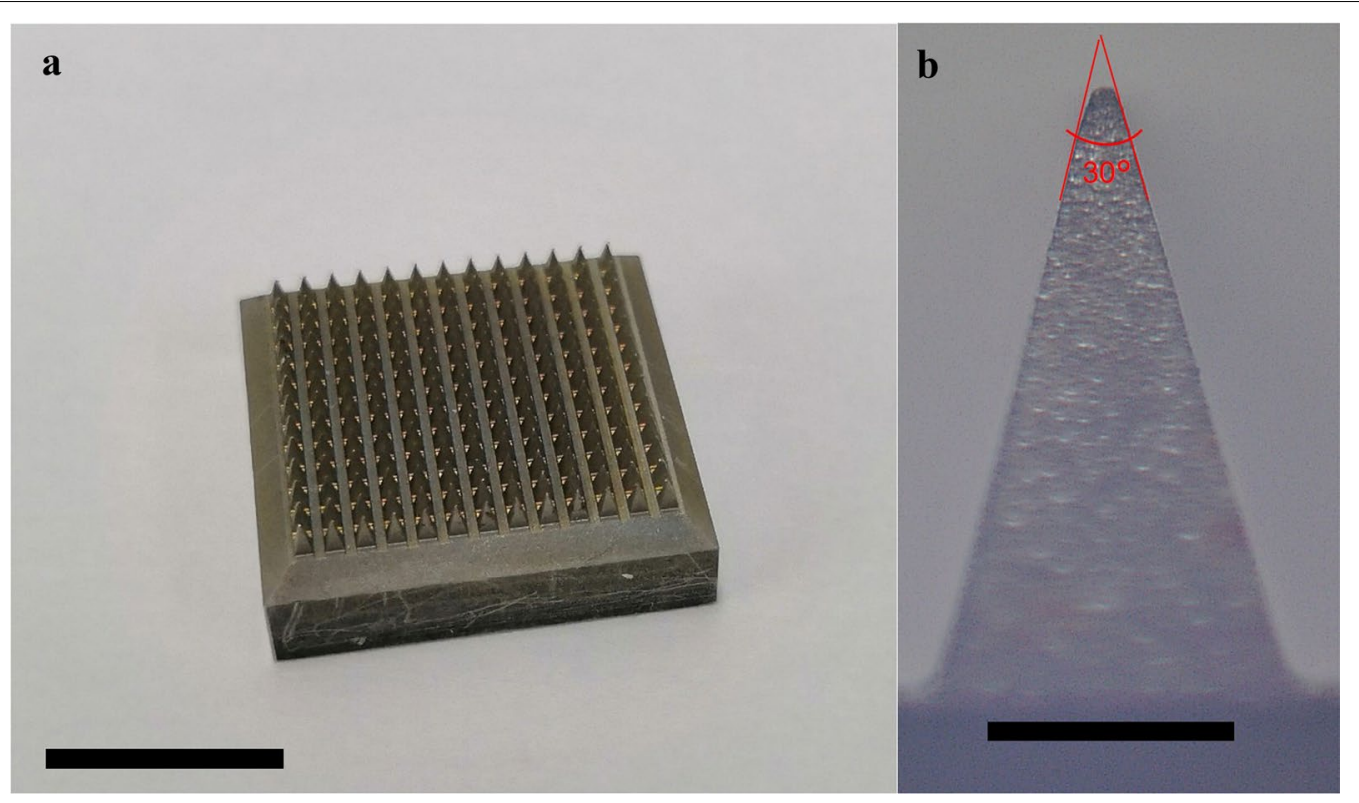

Fig. 1 Picture of $\mathbf{a}$ the metal mold used for the fabrication of the PDMS master mold and $\mathbf{b}$ a magnified view of one microneedle composing the metal mold (the scale bar corresponds to $1 \mathrm{~cm}$ on $\mathbf{a}$ and $500 \mu \mathrm{m}$ on $\mathbf{b}$ )

this purpose: only the bottom jaw is mobile, allowing to adjust the pressure by a lever. A soft material such as PDMS was placed against the array topped by a sheet of aluminum foil $(10 \mu \mathrm{m})$. Here, aluminum foil allows to separate physically the PDMS plate and the microneedles array in order to be easily handled and be used to simulate the skin for the dissolution properties. Aluminum foil has a shear strength higher than the skin, making aluminum a strict approximation of the skin $[36,37]$. Indeed, data from the metals handbook gave a shear strength of $325 \mathrm{MPa}$ for aluminum foil [36] against $27 \mathrm{MPa}$ for the human skin presented by Gallagher et al. [37]. To approximate the pressure exerted by a patient through his/her thumb, a pressure of $15 \mathrm{MPa}$ was applied to each array (1500 $\mathrm{g}$ on a surface of $9 \mathrm{~cm}^{2}$ ) for $2 \mathrm{~s}$. The bottom jaw of the press was adjusted before applying pressure. The strength between the jaws was raised up to $15 \mathrm{MPa}$ and maintained for $2 \mathrm{~s}$ before releasing it completely. For validation, the sample should be able to pierce through the aluminum foil and have more than $70 \%$ of its microneedles functional i.e. still up after the test. Samples fulfilling both criteria were labeled as 1 , those failing the criteria were labeled as 0 (Fig. 2). Figure 2a presents the piercing properties assessment immediately before applying pressure. The arrays were taped to a glass slide and wrapped using an aluminum foil. The system was placed in between the jaw and surmounted by a sheet of PDMS to simulate soft tissue under the skin. As depicted in Fig. 2b and c, almost all the microneedles pierced the aluminum foil and were still straight after the test; hence, this sample was labeled 1 . To better understand the set up for piercing assessment a schematic cross-section of the system is presented Fig. 2a. The microneedle array is facing up (microneedle side up), topped by an aluminum foil and covered with the PDMS sheet. Figure $2 b$ and $c$ shows $a$ successful pierced aluminum foil counted as a 1 .

Finally, the dissolution times of the samples were assessed by performing an experiment using an agarose gel with a concentration of $2 \%(\mathrm{w} / \mathrm{w})$, to mimic the mechanical properties of human skin [38]. The aim of the material was to pierce the skin, dissolve, and release drug or reveal the underlying microneedle as quickly as possible. Thus, if the array did not have any microneedles left after insertion, it was considered to be dissolved; in order to be the closest possible to actual skin, aluminum foil will not be removed for dissolution test, indeed, in real life the arrays is not directly in contact of the stratum corneum but put against the top surface of the skin. The moisture of the agarose gel will only interact with the microneedle as it is in the expected application where ISF and stratum corneum are separated with the array by the skin's top layer. The timer was initialized when the array touched the gel, and it was stopped upon complete dissolution of the microneedles. It should be noted that the dissolution times of samples labeled as 0 in the piercing assessment were not assessed. 


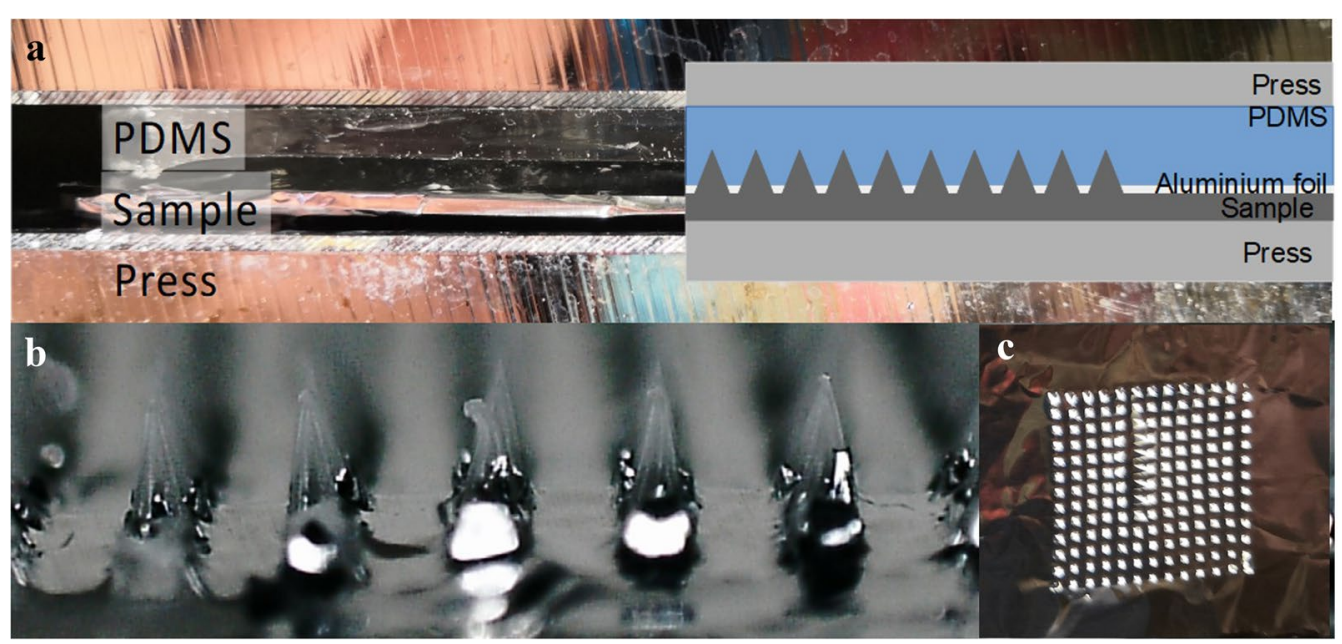

Fig. 2 Picture of $\mathbf{a}$ the press next to the schematic cross-section of the assessments, $\mathbf{b}$ an array passing the test with visible microneedles sticking out of the aluminum foil and $\mathbf{c}$ a piercing assessment top view

\section{Results and discussion Overall aspect}

Considering the array aspect, the three materials exhibited different morphologies without any observation tool (Fig. 3). HA arrays were white to translucent. They were stiff but exhibited flexibility. HA did not stick to the PDMS mold during peeling off owing to the opposite hydrophilic character of both materials, PDMS being hydrophobic [39] and HA being hydrophilic [40]. At $1 \%(w / w)$, the HA arrays were incomplete and difficult to peel off from the mold without breaking it. At 3 and $5 \%(w / w)$, both arrays appeared strong and were detached from the mold without breaking. Their microneedles were well defined and strong enough to withstand the pressure from a finger. Moreover, arrays made of 3 and $5 \%(\mathrm{w} / \mathrm{w})$ could be bend and folded without breaking (Fig. 3a-d). CMC arrays were white to translucent close to HA aspect. At a concentration of $1 \%(\mathrm{w} / \mathrm{w}), \mathrm{CMC}$ arrays were complete and cohesive. They presented no discontinuity of material or broken part but could be sheared if manipulated harshly. Both arrays with 3 and $5 \%(\mathrm{w} / \mathrm{w})$ concentration presented well-defined microneedles structures but seemed less strong than HA arrays at the same concentrations. Folding of the array was possible without breaking for 3 and $5 \%(w / w)$. Finally, alginate arrays went from a white to a light brown color

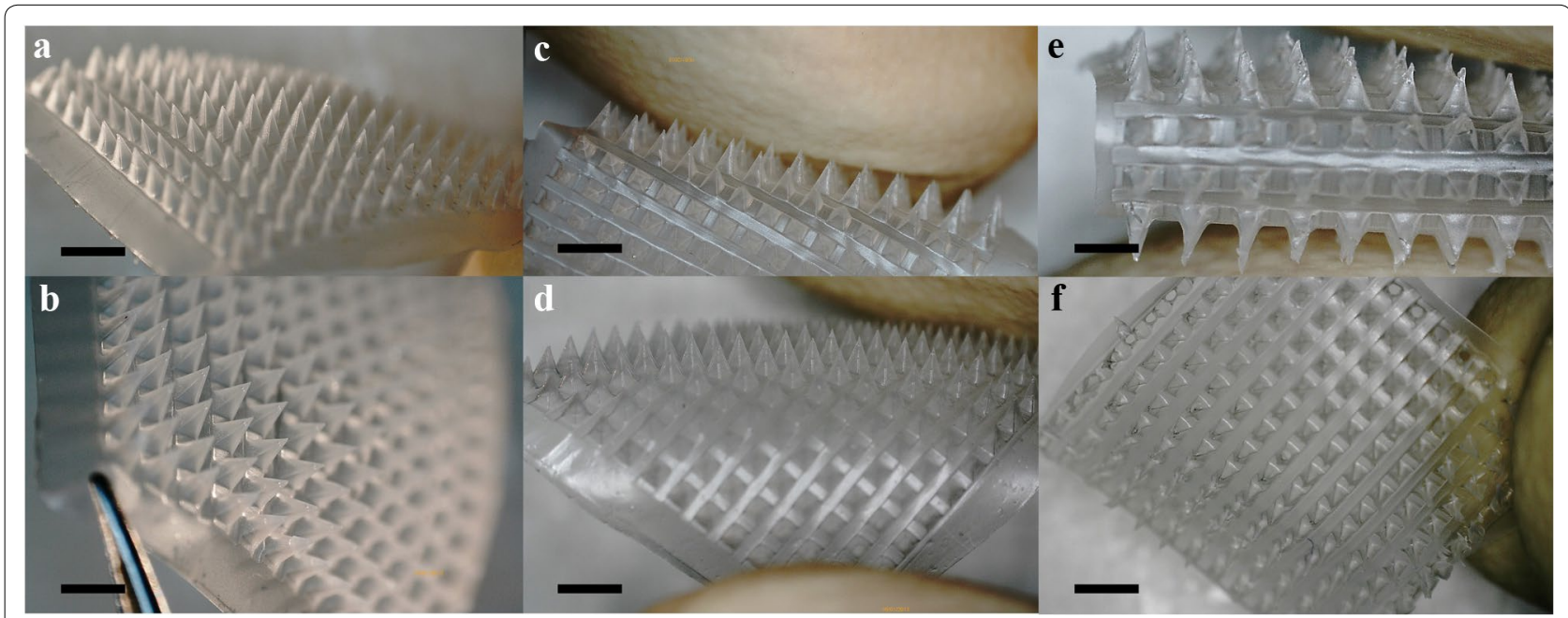

Fig. 3 Picture of $\mathbf{a}, \mathbf{b}$ an array made of $\mathrm{HA}$ at $3 \%(\mathrm{w} / \mathrm{w}), \mathbf{c}, \mathbf{d}$ an array made of $\mathrm{CMC}$ at $3 \%(\mathrm{w} / \mathrm{w}), \mathbf{e}, \mathbf{f}$ an array made of alginate at $3 \%(\mathrm{w} / \mathrm{w})(\mathrm{scale}$ bar corresponds to $1 \mathrm{~mm}$ ) 
during annealing. However, if the thermal treatment was stopped before the $2 \mathrm{~h}$ the alginate gave a white and flexible array. Still, independent from the annealing time, these arrays were brittle compared to $\mathrm{HA}$ and $\mathrm{CMC}$ arrays. A visible shrinkage was noticeable, the array did not cover the whole mold after the annealing process. It was considered that the color change was caused by such shrinkage. In addition, we observed that alginate arrays shrank during an annealing process and became thicker and denser providing a brittle and brown array.

Regarding the microneedles composing the arrays, HA and CMC exhibited well-defined microneedles. No missing microneedles were found. However, alginate array showed brittle and bent microneedles structures. They appeared to be smaller and bent at their tip (Fig. 3e). Moreover, some microneedles had their tips broken (Fig. 3f).

HA and CMC arrays appeared more defined and flexible than alginate array, with better looking microneedles and no broken tips.

\section{Geometrical consideration}

Fifty distinct microneedles were measured for geometrical evaluation. If microneedles had a tip width of less than $50 \mu \mathrm{m}$ and a width of approximately $500 \mu \mathrm{m}$, they were generally considered to cause less pain [41]. Actual specifications on the height were not provided, except the condition that it should not reach a nerve within the body (i.e., it should be less than $1000 \mu \mathrm{m}$ ) [41, 42]. In this study, as stated previously, each microneedle was shaped from a mold composed of microneedles shaped as a square pyramid, with a tip width of approximately $30 \mu \mathrm{m}$, total length of approximately $1200 \mu \mathrm{m}$, and width of approximately $600 \mu \mathrm{m}$ (Fig. 1). Moreover, the top angle was measured as approximately $30^{\circ}$, which enables easy penetration into skin. The tip width, height, and width of the microneedles are measured. The average values of each parameter were used to estimate the volume and morphology of each microneedle in the array. Microscopic view of the needle for each material examples are given Fig. 4.

As presented Fig. 4, microneedles made of $\mathrm{HA}$ and $\mathrm{CMC}$ were very similar, whereas alginate microneedles were observed to be shrunk and bent. In Fig. 4a, HA microneedle appeared to be empty in its middle. The same assumption could not be made by the picture given Fig. $4 \mathrm{~b}$ and $\mathrm{c}$ as for $\mathrm{CMC}$ and alginate made microneedles. Moreover, HA microneedles were well defined without asperities on their side. CMC microneedles came out less defined. Finally, alginate made microneedle are well defined but tilted or crooked, more prone to breaking when inserted into the skin.

Figure 5 shows the tip width as a function of the concentration, for each material studied.

In the case of $\mathrm{HA}, \mathrm{CMC}$, and alginate, the tip width was the lowest for the $3 \%(\mathrm{w} / \mathrm{w})$ solution of each material. At a concentration of $1 \%(\mathrm{w} / \mathrm{w})$, the tip width was of approximately $72 \pm 5 \mu \mathrm{m}$ for $\mathrm{HA}$ and $67 \pm 5 \mu \mathrm{m}$ for $\mathrm{CMC}$; however, it was double this value for alginate hence $118 \pm 24 \mu \mathrm{m}$. This high value, for the solution at $1 \%(\mathrm{w} / \mathrm{w})$, could be attributed to the low concentration of the solution. The entire amount of material had solidified onto the walls of the cavities and at the base of the array; hence, there was insufficient material to maintain the sharp tip. The tip was the sharpest at a concentration of $3 \%(\mathrm{w} / \mathrm{w})$. It was less than $48 \pm 8 \mu \mathrm{m}$ for $\mathrm{HA}, 40 \pm 5 \mu \mathrm{m}$ for $\mathrm{CMC}$, and $57 \pm 4 \mu \mathrm{m}$ for alginate. Finally, the tip width increased for each material; indeed, the solution

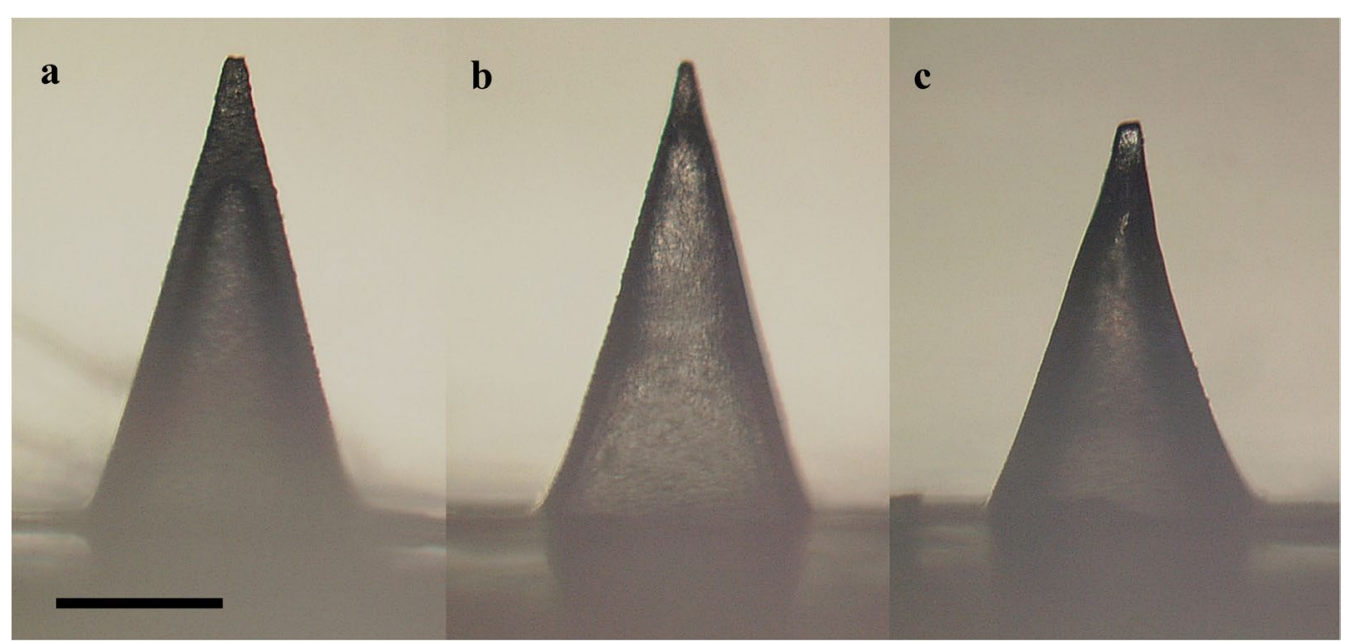

Fig. 4 Optical pictures of a microneedle made of $\mathbf{a} \mathrm{HA}$ at $3 \%(\mathrm{w} / \mathrm{w}), \mathbf{b} \mathrm{CMC}$ at $3 \%(\mathrm{w} / \mathrm{w})$ and $\mathbf{c}$ alginate at $3 \%(\mathrm{w} / \mathrm{w})$. (scale bar corresponds to $500 \mu \mathrm{m})$ 


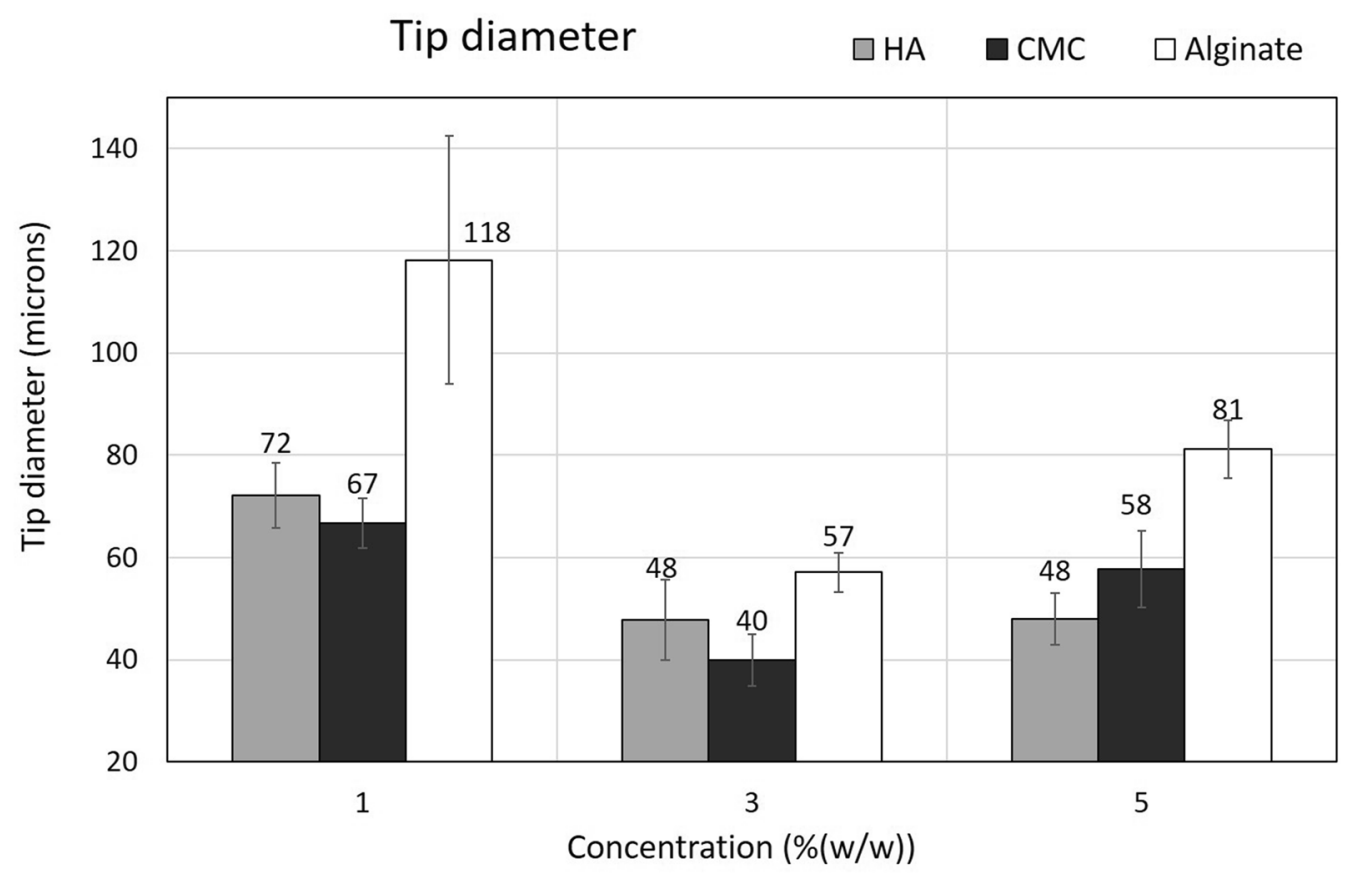

Fig. 5 Tip width as a function of the concentration $(\%(w / w))$ for each material studied (HA (grey), CMC (black) and alginate (white))

could not completely fit the cavity during thermal treatment due to increasing viscosity, resulting in a wider tip of the microneedle. For a concentration of $5 \%(w / w)$, the tip width was $48 \pm 6 \mu \mathrm{m}, 58 \pm 7 \mu \mathrm{m}$ and $81 \pm 6 \mu \mathrm{m}$ for $\mathrm{HA}, \mathrm{CMC}$, and alginate, respectively. As stated previously, for a painless insertion into the skin, a tip width of less than $50 \mu \mathrm{m}$ is required, and both solutions of HA and $\mathrm{CMC}$ fulfilled these parameters at a concentration of $3 \%(w / w)$. However, alginate did not meet the requirements for the 1,3 , and $5 \%(\mathrm{w} / \mathrm{w})$ concentrations. Alginate arrays being more brittle than HA and CMC arrays, this high value could be attributed to broken tips.

The variations in the height of the microneedles are plotted in Fig. 6.

For each material, some variations were noticeable, but microneedle array's heights gravitated to approximately $1000 \mu \mathrm{m}$ (Fig. 6). The height of the HA arrays kept increasing from $1012 \pm 34 \mu \mathrm{m}$ for $1 \%(\mathrm{w} / \mathrm{w})$, to $1033 \pm 21 \mu \mathrm{m}$ at $3 \%(\mathrm{w} / \mathrm{w})$ to reach $1077 \pm 18 \mu \mathrm{m}$ for $5 \%(\mathrm{w} / \mathrm{w})$ concentration. For CMC, height started from $1086 \pm 23 \mu \mathrm{m}$ at $1 \%(\mathrm{w} / \mathrm{w})$, decreased to $1074 \pm 23 \mu \mathrm{m}$ at $3 \%(\mathrm{w} / \mathrm{w})$ and $971 \pm 34 \mu \mathrm{m}$ for $5 \%(\mathrm{w} / \mathrm{w})$ concentration. For the alginate arrays, height increased from $930 \pm 50 \mu \mathrm{m}$ to $1026 \pm 27 \mu \mathrm{m}$ before decreasing to $988 \pm 23 \mu \mathrm{m}$ for 1,3 and $5 \%(\mathrm{w} / \mathrm{w})$ concentration, respectively. Low value for alginate compared to HA and CMC can be explained by the visible shrinkage happening for alginate arrays. Moreover, broken tips, especially for the $1 \%(\mathrm{w} / \mathrm{w})$ arrays leads to a significant difference. For $3 \%(w / w)$ arrays, given the height of the three materials, alginate appeared to have less broken tips than for $1 \%(\mathrm{w} / \mathrm{w})$, raising the height of the arrays to comparable value with HA and CMC. Finally, for a concentration of $5 \%(w / w)$, HA kept a high value compared to CMC and alginate arrays. This gap can be explained by the increasing of the viscosity of the solution for $\mathrm{CMC}$ and alginate when increasing the concentration. This effect added to the brittle characteristic of the alginate array led to more broken tips and a lower height.

Figure 7 presents the variation of width for each array as a function of their concentrations.

As shown in Fig. 7, a global tendency can be seen. Indeed, width was lower for alginate for each concentration. It can be attributed to the shrinkage of alginate arrays. HA array's width were around $600 \mu \mathrm{m}$. More precisely, respectively, a width of $610 \pm 32 \mu \mathrm{m}, 600 \pm 12 \mu \mathrm{m}$, and $608 \pm 10 \mu \mathrm{m}$ for 1,3 and $5 \%(\mathrm{w} / \mathrm{w})$ for HA. CMC array's width went from $608 \pm 16 \mu \mathrm{m}$ for $1 \%(\mathrm{w} / \mathrm{w})$, $598 \pm 16$ at $3 \%(\mathrm{w} / \mathrm{w})$ to finally reach $539 \pm 17 \mu \mathrm{m}$ for $5 \%(\mathrm{w} / \mathrm{w})$. For both $1 \%(\mathrm{w} / \mathrm{w})$ and $3 \%(\mathrm{w} / \mathrm{w})$ concentration, the microneedle's made of HA and CMC appeared to be similar. However, for a concentration of $5 \%(\mathrm{w} / \mathrm{w})$, a shrinkage is noticeable through the geometrical measurement. Indeed, by naked eye, this phenomenon was not noticeable. Finally, for alginate arrays, a lower width was expected. It ranges from $574 \pm 26 \mu \mathrm{m}$ for $1 \%(\mathrm{w} / \mathrm{w})$ 


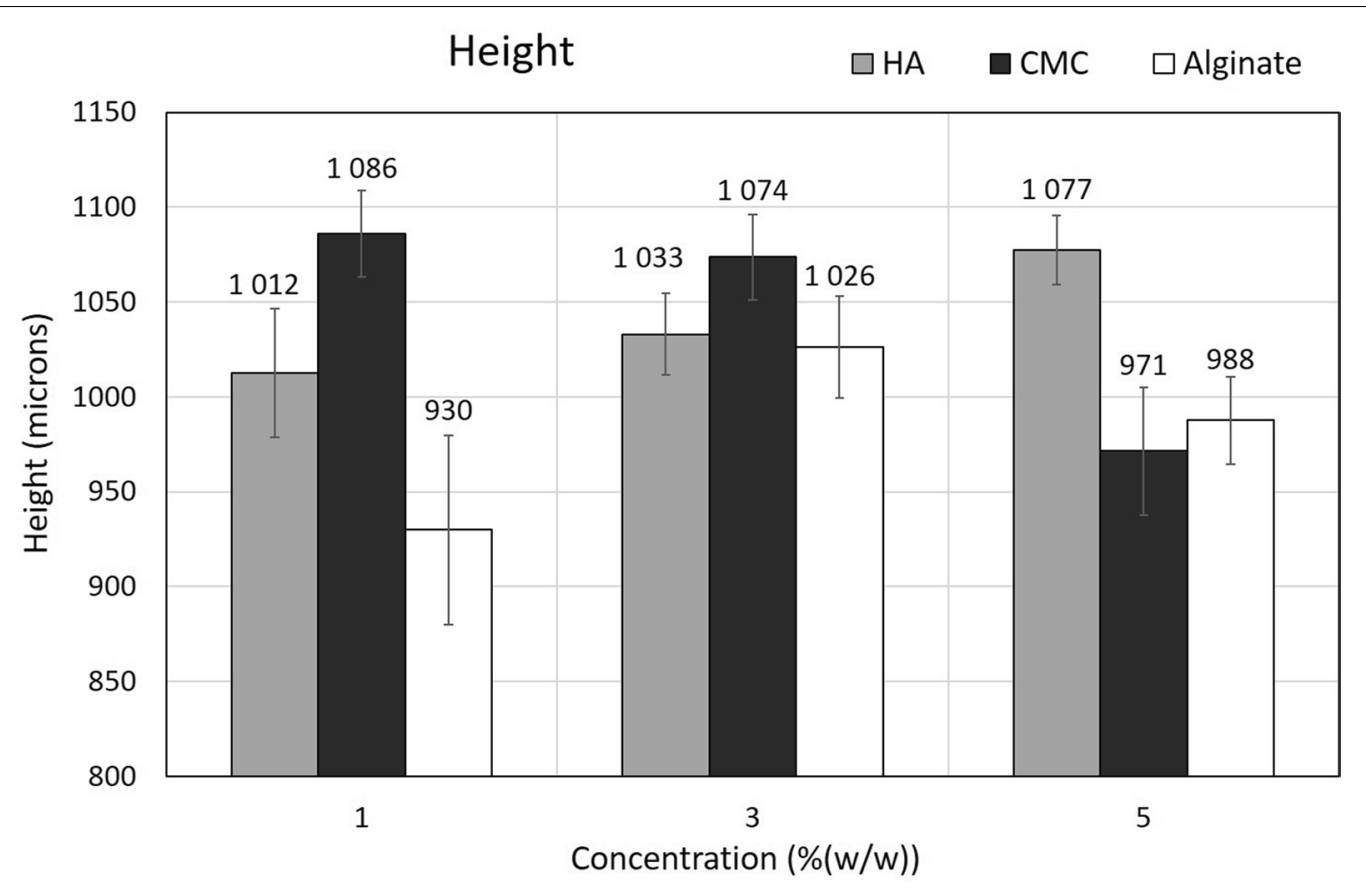

Fig. 6 Microneedle's height as a function of the concentration for HA (grey), CMC (black) and alginate (white)

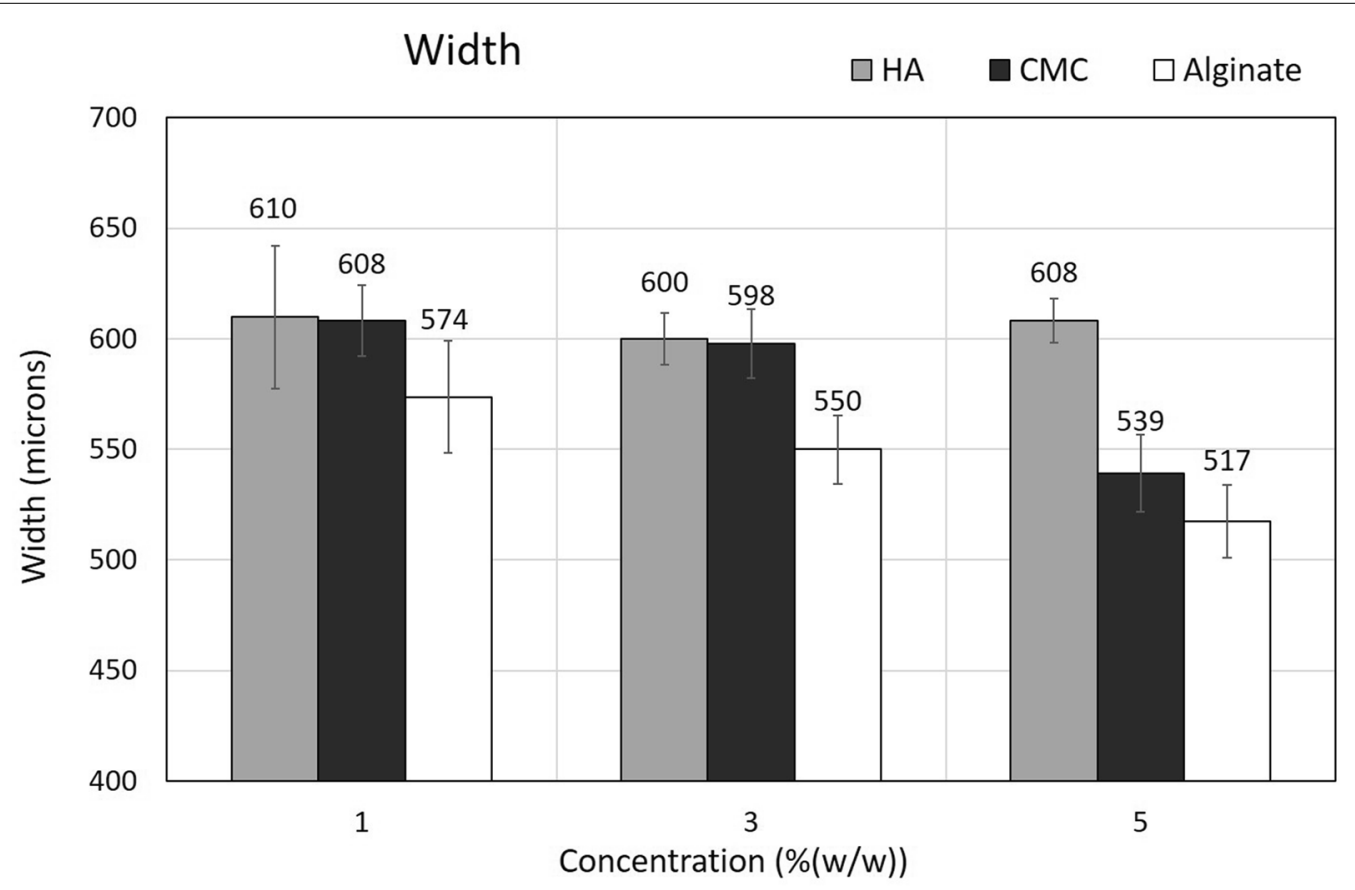

Fig. 7 Microneedle's base width as a function of the concentration for HA (grey), CMC (black) and alginate (white)

to $550 \pm 15 \mu \mathrm{m}$ at $3 \%(\mathrm{w} / \mathrm{w})$ to reach a final $517 \pm 17 \mu \mathrm{m}$ at $5 \%(\mathrm{w} / \mathrm{w})$ concentration. Besides appearing shrunk by the naked eye, geometrical measurement through a microscope confirmed the shrinkage of alginate array. This phenomenon appeared to be exacerbated by 
increasing the concentration. To measure shrinkage, width measurement seemed to be the parameters of choice.

All the measurements are summarized in Table 1.

The relative error given in the table were calculated using a statistical Student's t-distribution law for a correlation coefficient of 0.95 .

Figure 8 presents the comparative schematic of each average microneedles made in this work. Shrinkage is visible between alginate array and the other materials.

Regarding the geometrical aspect, for HA arrays, $3 \%(\mathrm{w} / \mathrm{w})$ and $5 \%(\mathrm{w} / \mathrm{w})$ emerged as optimal microneedles for helping to break the skin, close to the requirements specifications stated in previously. CMC arrays met the criteria introduced for a painless microneedle at a concentration of $3 \%(w / w)$. Finally, alginate, despite their shrinkage, could not reach the tip size criteria of less than $50 \mu \mathrm{m}$ tip size.

Since shrinkage is noticeable for CMC at $5 \%(\mathrm{w} / \mathrm{w})$ and every alginate array, it had to be determined for each material. The volume of each needles was determined by calculating the volume using the tip size, height, and width measured previously. To be comparable and relevant, the volume had to be calculated by considering the sharpest tip i.e. tip width being the smallest possible, tending to 0 . To simplify the calculation, the microneedles were considered in the shape of a regular pyramid. The volume $(V)$ of a square based pyramid is given by Eq. (1),

$$
V=\frac{c^{2} \times h}{3}
$$

Table 1 Recapitulative table of each array's microneedle parameters

\begin{tabular}{lccc}
\hline \%(w/w) & $\mathbf{1}$ & $\mathbf{3}$ & $\mathbf{5}$ \\
\hline Hyaluronic acid & & & \\
Tip $(\mu \mathrm{m})$ & $72 \pm 5$ & $48 \pm 8$ & $48 \pm 6$ \\
Height $(\mu \mathrm{m})$ & $1012 \pm 34$ & $1033 \pm 21$ & $1077 \pm 18$ \\
Width $(\mu \mathrm{m})$ & $610 \pm 32$ & $600 \pm 12$ & $608 \pm 10$ \\
Carboxymethyl cellulose & & \\
Tip $(\mu \mathrm{m})$ & $67 \pm 5$ & $40 \pm 5$ & $58 \pm 7$ \\
Height $(\mu \mathrm{m})$ & $1086 \pm 23$ & $1074 \pm 23$ & $971 \pm 34$ \\
Width $(\mu \mathrm{m})$ & $608 \pm 16$ & $598 \pm 16$ & $539 \pm 17$ \\
Alginate & & & \\
Tip $(\mu \mathrm{m})$ & $118 \pm 24$ & $57 \pm 4$ & $81 \pm 6$ \\
Height $(\mu \mathrm{m})$ & $930 \pm 50$ & $1026 \pm 27$ & $988 \pm 23$ \\
Width $(\mu \mathrm{m})$ & $574 \pm 26$ & $550 \pm 15$ & $517 \pm 17$ \\
\hline
\end{tabular}

The relative error given in the table were calculated using a statistical Student's t-distribution law for a correlation coefficient of 0.95

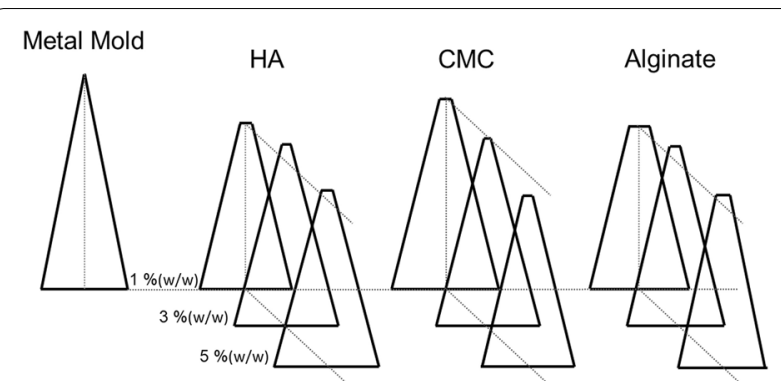

Fig. 8 Schematic comparison of each microneedle's as a function of their concentration and material used

where $\mathrm{c}$ is the side of the square base and $\mathrm{h}$ the total height.

Nevertheless, the total height of the pyramid was not accessible, and therefore, had to be calculated. Figure 9 presents a schematic of the needle, wherein the known value is indicated by a dotted line.

By determining the values of the base sides of both pyramids (upper and lower pyramid), we can easily calculate the diagonal. Using this value of the diagonal, the height of the small pyramid can be calculated, which in turn yields the volume of the biggest pyramid. Comparing the complete pyramids for each microneedle will enable us to easily compare one microneedle to another.

Thales theorem provides an equality where the half-diagonal of the small pyramid (CD) over the

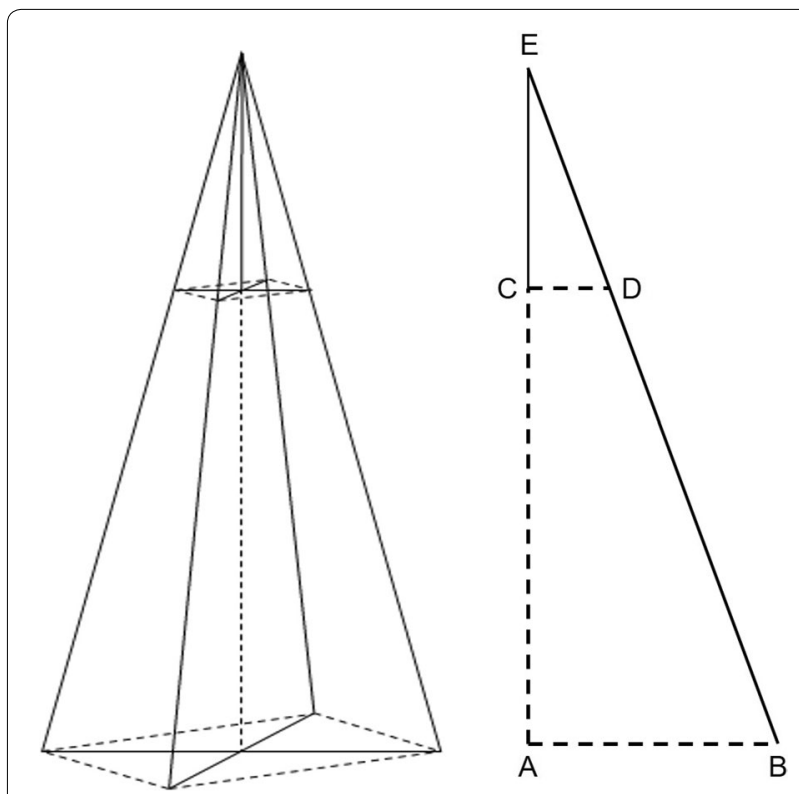

Fig. 9 Schematic of a single microneedle for calculating the total pyramid's volume 
half-diagonal of the whole pyramid $(A B)$ equals the top pyramid height $(\mathrm{CE})$ over the total height $(\mathrm{AE})$, where $(\mathrm{AC})$ is the previously measured height.

$$
\frac{C D}{A B}=\frac{C E}{A E} \text { where } A E=A C+C E
$$

When extracting the unknown $\mathrm{CE}$, we end up with the Eq. (3) below,

$$
C E=\frac{C D \times A C}{A B \times\left(1-\frac{C D}{A B}\right)}
$$

By determining $\mathrm{CE}$, we can calculate $\mathrm{AE}$ using Eq. (2); thus, the total volume of the pyramid can be obtained.

Table 2 presents the different volumes and their comparison with the actual master mold (i.e., the shrinkage).

Globally, shrinkage occurred for every material. For HA, shrinkage was invisible by naked eye but after calculation, all arrays shrank. Respectively, HA arrays shrank of $3.6,8.9$ and $2.4 \%$ of the desired metal mold volume. This value stayed under $10 \%$ of shrinkage. Low shrinkage of HA has been observed at around 6\% in volume by Winter et al. [43]. CMC arrays shrinkages increased from 0 to 7.2 and finally $28.6 \%$ for respectively 1,3 and $5 \%(\mathrm{w} / \mathrm{w})$. While CMC array was thermally treated, the water content decreased, forming a hydrogel in the mold. This hydrogel filled the mold and continued to undergo thermal treatment, leading to a shrinkage. By increasing the concentration, the hydrogel formation by CMC occurred sooner as a network could be formed by the presence of more molecules of CMC. Arrays made from higher concentration led to higher shrinkage. Shrinkage of CMC array made of $5 \%(w / w)$ concentration observed

Table 2 Volume calculated by using Eq. (2) and shrinkage percentage, with standard deviation calculated

\begin{tabular}{|c|c|c|c|}
\hline Master mould & Volume $\left(10^{6} \mu \mathrm{m}^{3}\right)$ & V/V total & Shrinkage (\%) \\
\hline & 148 & & \\
\hline \multicolumn{4}{|l|}{$\mathrm{HA}$} \\
\hline $1 \%(w / w)$ & $142 \pm 0.02$ & 0.96 & 3.6 \\
\hline $3 \%(w / w)$ & $134 \pm 0.003$ & 0.91 & 8.9 \\
\hline $5 \%(w / w)$ & $144 \pm 0.001$ & 0.98 & 2.4 \\
\hline \multicolumn{4}{|l|}{ CMC } \\
\hline $1 \%(w / w)$ & $150 \pm 0.003$ & 1.02 & 0.0 \\
\hline $3 \%(w / w)$ & $137 \pm 0.003$ & 0.93 & 7.2 \\
\hline $5 \%(w / w)$ & $105 \pm 0.006$ & 0.71 & 28.6 \\
\hline \multicolumn{4}{|l|}{ Alginate } \\
\hline $1 \%(w / w)$ & $128 \pm 0.2$ & 0.87 & 13.0 \\
\hline $3 \%(w / w)$ & $115 \pm 0.003$ & 0.78 & 21.8 \\
\hline $5 \%(w / w)$ & $105 \pm 0.003$ & 0.71 & 29.2 \\
\hline
\end{tabular}
for a student law of 0.95 during geometrical measurement has been confirmed. Finally, alginate arrays showed more shrinkage than HA and CMC. The shrinkage increased from 13 to 21.8 to reach $29.2 \%$ for 1,3 and $5 \%(\mathrm{w} / \mathrm{w})$, respectively. Previous studies have also reported the shrinkage of alginate; Walker et al. showed that objects composed of alginate tend to experience shrinkage [44]. A shrinkage of up to $50 \%$ after 30 min of thermal treatment was observed. In this study, the shrinkage was caused by thermal treatment, as energy was transferred to the matter, enabling it to reach its equilibrium state. Moreover, for alginate arrays, it was shown that shrinkage continues even after the completion of thermal treatment [44].

In addition, a high shrinkage can be an obstacle for the underlying microneedle arrays because it creates tension, which could lead to potential breakages. A material design that is viable for mechanical enhancement should not exert tension on the system. In this study, the best candidates for enhancement were the HA and CMC arrays, with a shrinkage of less than $10 \%$ for a concentration of $3 \%(w / w)$.

\section{Piercing abilities}

Regarding the piercing properties, Fig. 10 shows microneedle's piercing as a function of the concentration for each material.

Being a binary test, the array of the microneedles with more than $70 \%$ chance of survival were labeled as 1 otherwise labeled as 0 : the results were plotted as a percentage of success. As expected from the geometrical and other overall aspect results, the weakest arrays to pierce the aluminum foil were made of the $1 \%(\mathrm{w} / \mathrm{w})$ concentration. Indeed, no microneedles survived the piercing test for these arrays for every material and every concentration.

HA yielded the best results; all the samples passed the test at concentrations of $3 \%(\mathrm{w} / \mathrm{w})$ and $5 \%(\mathrm{w} / \mathrm{w})$; attributable to their sharp tips. CMC had seen its arrays pierce at $75 \%$ for the concentration at $3 \%(\mathrm{w} / \mathrm{w})$ and $87.5 \%$ for its $5 \%(\mathrm{w} / \mathrm{w})$ concentration. Even if CMC tips were smaller or close to those of HA, piercing was less efficient. This result can be explained given the picture of microneedle provided Fig. 4b. CMC microneedles appeared less defined than HA microneedles, leading to potential breakage and thus less efficiency in piercing capabilities. The alginate array at a concentration of $3 \%(w / w)$ appeared to pierce the aluminum foil more frequently than that at a concentration of $5 \%(\mathrm{w} / \mathrm{w})$. This decreasing can be explained by the increasing of tip size for alginate arrays from $57 \mu \mathrm{m}$ to $81 \mu \mathrm{m}$. However, even if CMC is sharper than alginate for a concentration of $3 \%(w / w)$, alginate pierce more often the aluminum foil: alginate arrays are mechanically more stable than $\mathrm{CMC}$ arrays for $3 \%(\mathrm{w} / \mathrm{w})$ concentration. To go further, if comparing 


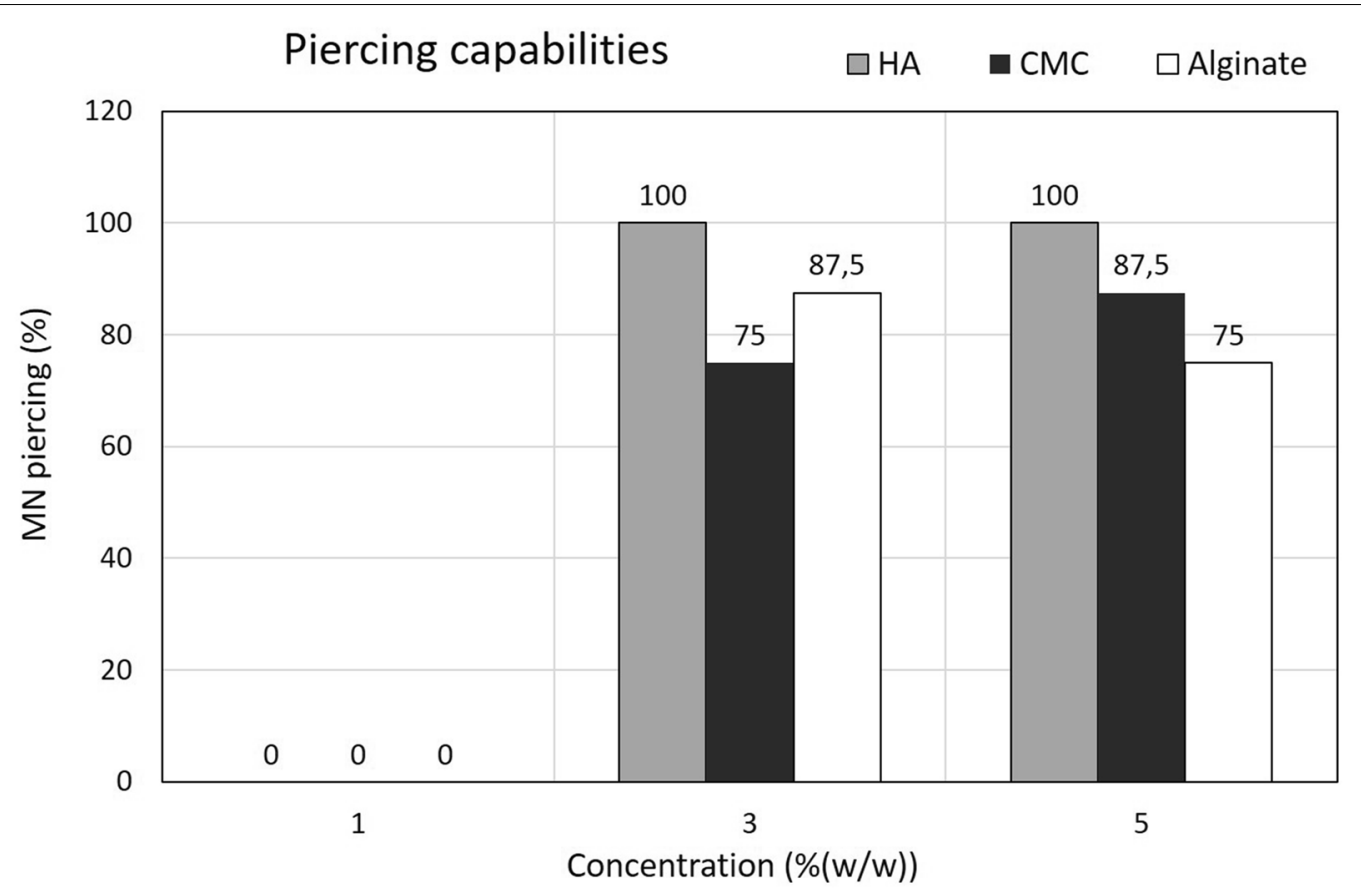

Fig. 10 Piercing capabilities as a function of the concentration for each material (HA (grey), CMC (black) and alginate (white))

$3 \%(\mathrm{w} / \mathrm{w}) \mathrm{CMC}$ and $5 \%(\mathrm{w} / \mathrm{w})$ alginate, the same number of arrays, successfully penetrated the aluminum foil, with a tip size twice bigger for alginate. This corroborate the mechanical strength of the alginate compared to CMC. Two parameters rose as key features for a microneedles array: a sharp tip as well as strong mechanical properties. Indeed, even if HA appeared less strong than alginate, they fully succeeded in piercing the aluminum foil thanks to their sharp tip. CMC resulted in weaker arrays than alginate but given their sharp tips, succeeded more often than alginate array for a concentration of $3 \%(w / w)$. The converse was true for $5 \%(\mathrm{w} / \mathrm{w})$ concentration.

Finally, the arrays passing the tests were put through the dissolution test. There was no point in testing arrays that were not strong enough to pierce the aluminum foil. Indeed, if they did not break the skin barrier, they could not dissolve by reaching ISF.

\section{Dissolution time}

Figure 11 presents the dissolution time as a function of the concentration of $\mathrm{HA}, \mathrm{CMC}$, and alginate.

As shown in Fig. 11, when the concentration increased from 3 to $5 \%(\mathrm{w} / \mathrm{w})$, the dissolution time increased for each material. It went from $1 \mathrm{~min} 30 \mathrm{~s}$ for HA arrays of $3 \%(\mathrm{w} / \mathrm{w})$ to approximately $2 \mathrm{~min}$ for $5 \%(\mathrm{w} / \mathrm{w})$. For CMC arrays, the dissolution time was approximately $2 \mathrm{~min}$ against $3 \mathrm{~min} 20 \mathrm{~s}$ for respectively $3 \%(\mathrm{w} / \mathrm{w})$ and $5 \%(\mathrm{w} / \mathrm{w})$.
Finally, array made of alginate took approximately $2 \mathrm{~min}$ for $3 \%(\mathrm{w} / \mathrm{w})$ and more than $3 \mathrm{~min} 30 \mathrm{~s}$ for $5 \%(\mathrm{w} / \mathrm{w})$.

Figure 12, carbon skeleton of HA, CMC and alginate are presented. HA includes small pendant groups composed of one carboxylic group, one amid group and several alcoholic functions by recurring unit (Fig. 12a). CMC presents a smaller recurring unit, composed of alcohol terminated group or 2 carbons carboxylic group (Fig. 12b). Finally, alginate is composed of only 1 carbon carboxylic group and alcohol (Fig. 12c).

HA by its carbon skeleton allows a quicker dissolution. Indeed, the polymer chain is not sterically hindered allowing water to penetrate between the polymer chain to dissolve it. Less $\mathrm{H}$ bonds are noticeable because of less couple carboxylic/alcoholic group within the branched function. Regarding, CMC and alginate, the longer time of dissolution can be explained on a chemical and physical point of view. CMC is composed of longer branched group, allowing a better link between the chain polymers. Moreover, $\mathrm{H}$ bonds can be found between the carboxylic group and the hydrogen of its branched group. Finally, alginate, being composed of only alcoholic group and carboxylic group, has a higher stability due to a large amount of $\mathrm{H}$ bonds. Moreover, its bigger shrinkage, allows water to penetrate less in between the polymer chain.

From a dissolution point of view and an aspect for the application, a successful piercing of the skin followed 


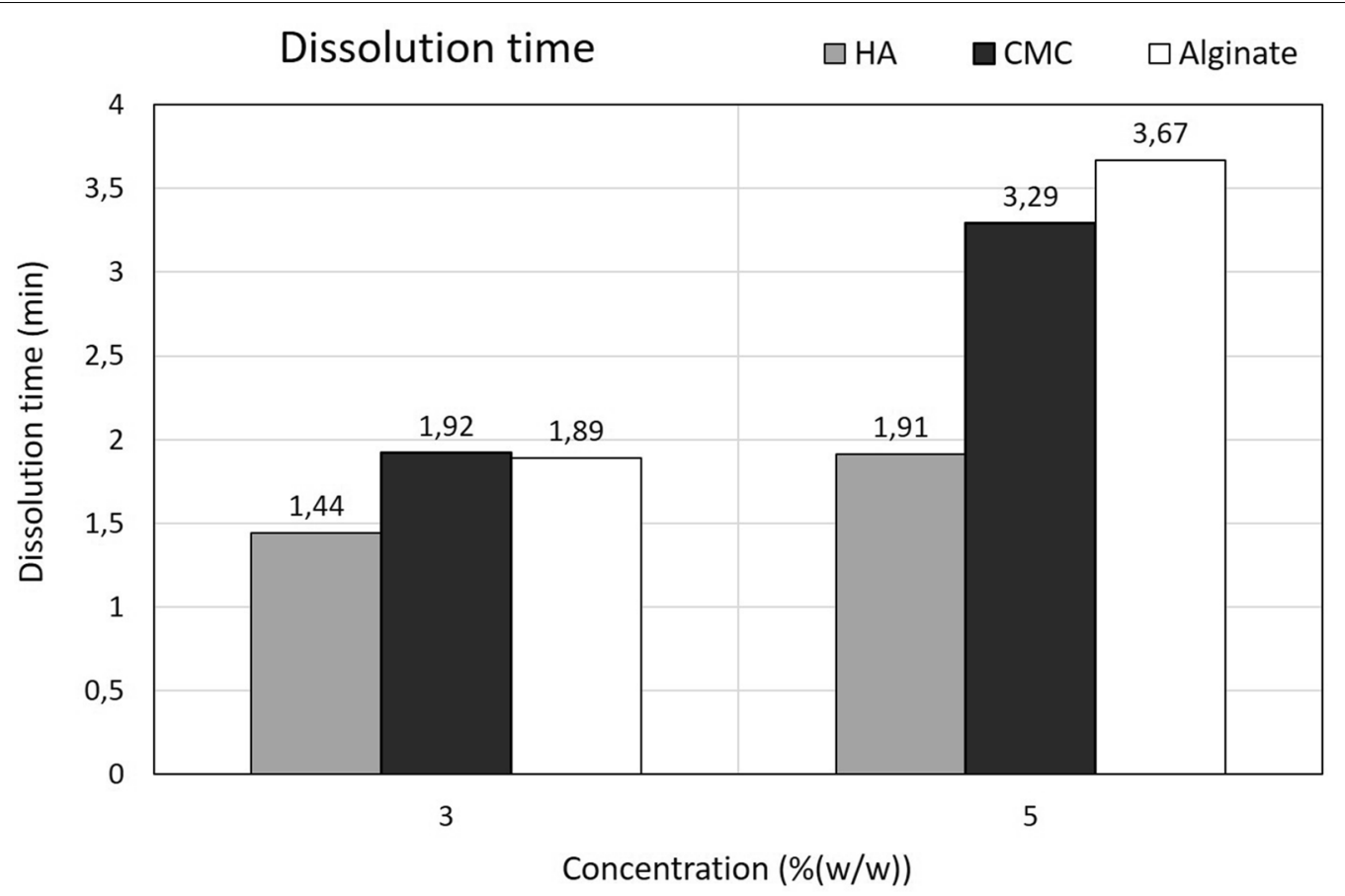

Fig. 11 Dissolution time as a function of the concentration for each material (HA (grey), CMC (black) and alginate (white))
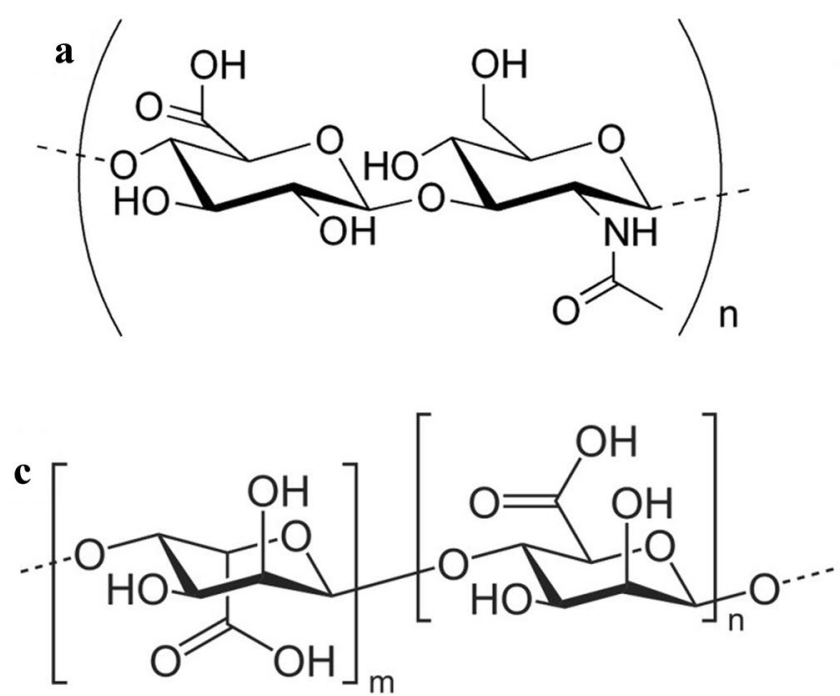

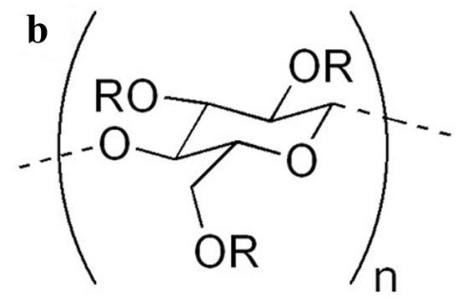

$\mathrm{R}=\mathrm{H}$ or $\mathrm{CH}_{2} \mathrm{CO}_{2} \mathrm{H}$

Fig. 12 Molecular chain of $\mathbf{a} \mathrm{HA}, \mathbf{b} C M C$ and $\mathbf{c}$ alginate polymers

by a fast dissolution, HA arrays at 3\%(w/w) are considered to yield good results.

\section{Conclusion}

In this study, three bio-compatible and biodegradable materials which were broadly used, i.e., HA, CMC and alginate, were evaluated as the material for microneedle arrays and compared with each other. Considering geometrical aspect, each material made of $3 \%(\mathrm{w} / \mathrm{w})$ yields microneedles which are the closest to the requirement specifications. HA arrays gave arrays composed of microneedles with a tip size of approximately $48 \pm 8 \mu \mathrm{m}$, a height of approximately $1033 \pm 21 \mu \mathrm{m}$ and a width of approximately $600 \pm 12 \mu \mathrm{m}$, shrinkage was of $8.9 \%$. 
Arrays made of CMC yielded microneedles with a tip size of approximately $40 \pm 5 \mu \mathrm{m}$, a height of approximately $1074 \pm 23 \mu \mathrm{m}$ and a width of approximately $598 \pm 16 \mu \mathrm{m}$ with a shrinkage of $7.2 \%$. Finally, alginate array's microneedles resulted in a tip size of approximately $57 \pm 4 \mu \mathrm{m}$, a height of approximately $1026 \pm 27 \mu \mathrm{m}$ and a width of approximately $550 \pm 15 \mu \mathrm{m}$ and a shrinkage of $21.8 \%$. Regarding the piercing capabilities, HA at $3 \%(\mathrm{w} / \mathrm{w})$ pierced the aluminum foil successfully. Only $87.5 \%$ of array made of $\mathrm{CMC}$ at $5 \%(\mathrm{w} / \mathrm{w})$ and alginate at $3 \%(\mathrm{w} / \mathrm{w})$ passed the piercing test, being the best result for $\mathrm{CMC}$ and alginate material. Fastest dissolution time were for the array made of $3 \%(\mathrm{w} / \mathrm{w})$ for each material under $2 \mathrm{~min}$. Moreover, HA at 3\%(w/w) yielded the fastest dissolution with $1 \mathrm{~min}$ and $30 \mathrm{~s}$.

Regarding the aspect of applications, i.e. piercing the skin efficiently and dissolving rapidly to reveal underlying microneedles, we concluded that the array made of $\mathrm{HA}$ at $3 \%(\mathrm{w} / \mathrm{w})$ as the best material and concentration considering specified dimensions, piercing efficiency and dissolution time.

\section{Acknowledgements}

This work was supported by JSPS standard program (International Research Fellow of Japan Society for the Promotion of Science (Postdoctoral Fellowships for Research in Japan)).

\section{Authors' contributions}

GB did all experiments, data analysis and writing. NT provided a valuable expertise on precision micro engineering and microneedle. $\mathrm{HL}$ and $\mathrm{BL}$ provided expertise and microneedles fabrication as well as proofreading the manuscript. JP provided accurate and welcomed corrections making the second manuscript way better than the first submission. BJK provided a laboratory to do the experiments and proofread this work. All authors read and approved the final manuscript.

\section{Funding}

This work was supported by JSPS standard program (International Research Fellow of Japan Society for the Promotion of Science (Postdoctoral Fellowships for Research in Japan) 19P19725).

\section{Availability of data and materials}

The datasets used and analysed during the current study are available from the corresponding author on reasonable request.

\section{Competing interests}

The authors declare that they have no competing interests.

\section{Author details}

${ }^{1}$ LIMMS/CNRS-IIS UMI 2820, The University of Tokyo, Tokyo, Japan. ${ }^{2}$ Institute of Industrial Science, The University of Tokyo, Tokyo, Japan

Received: 28 April 2020 Accepted: 8 July 2020

Published online: 25 July 2020

\footnotetext{
References

1. Fogh-Andersen N, Altura BM, Altura BT, Siggaard-Andersen O (1995) Composition of interstitial fluid. Clin Chem 41:1522-1525. https://doi. org/10.1093/clinchem/41.10.1522

2. Touitou E (2002) Drug delivery across the skin. Expert Opin Biol Ther 2:723-733. https://doi.org/10.1517/14712598.2.7.723
}

3. Ventrelli L, Marsilio Strambini L, Barillaro G (2015) Microneedles for transdermal biosensing: current picture and future direction. Adv Healthc Mater 4:2606-2640. https://doi.org/10.1002/adhm.201500450

4. Kleinknecht RA, Thorndike RM, Walls MM (1996) Factorial dimensions and correlates of blood, injury, injection and related medical fears: cross validation of the medical fear survey. Behav Res Ther 34:323-331. https:// doi.org/10.1016/0005-7967(95)00072-0

5. Fassler D (1985) The fear of needles in children. Am J Orthopsychiatry 55:371-377. https://doi.org/10.1111/j.1939-0025.1985.tb03452.x

6. Nir Y, Paz A, Sabo E, Potasman I (2003) Fear of injections in young adults: prevalence and associations. Am J Trop Med Hyg 68:341-344. https://doi. org/10.4269/ajtmh.2003.68.341

7. Wright S, Yelland M, Heathcote K et al (2009) Fear of needles -nature and prevalence in general practice. Aust Fam Physician 38:172

8. Samant PP, Prausnitz MR (2018) Mechanisms of sampling interstitial fluid from skin using a microneedle patch. PNAS 115:4583-4588. https://doi. org/10.1073/pnas.1716772115

9. Takeuchi K, Takama N, Kim B et al (2019) Microfluidic chip to interface porous microneedles for ISF collection. Biomed Microdevices 21:28. https //doi.org/10.1007/s10544-019-0370-4

10. Hong X, Wei L, Wu F et al (2013) Dissolving and biodegradable microneedle technologies for transdermal sustained delivery of drug and vaccine. Drug Des Devel Ther 7:945-952. https://doi.org/10.2147/DDDT.S44401

11. Kim Y-C, Park J-H, Prausnitz MR (2012) Microneedles for drug and vaccine delivery. Adv Drug Deliv Rev 64:1547-1568. https://doi.org/10.1016/j. addr.2012.04.005

12. Sivamani RK, Stoeber B, Wu GC et al (2005) Clinical microneedle injection of methyl nicotinate: stratum corneum penetration. Skin Res Technol 11:152-156. https://doi.org/10.1111/j.1600-0846.2005.00107.x

13. Nam YS, Park TG (1999) Biodegradable polymeric microcellular foams by modified thermally induced phase separation method. Biomaterials 20:1783-1790. https://doi.org/10.1016/S0142-9612(99)00073-3

14. Bollella P, Sharma S, Cass AEG, Antiochia R (2019) Microneedle-based biosensor for minimally-invasive lactate detection. Biosens Bioelectron 123:152-159. https://doi.org/10.1016/j.bios.2018.08.010

15. Wang M, Hu L, Xu C (2017) Recent advances in the design of polymeric microneedles for transdermal drug delivery and biosensing. Lab Chip 17:1373-1387. https://doi.org/10.1039/C7LC00016B

16. Romanyuk AV, Zvezdin VN, Samant P et al (2014) Collection of analytes from microneedle patches. Anal Chem 86:10520-10523. https://doi. org/10.1021/ac503823p

17. Prausnitz MR (2004) Microneedles for transdermal drug delivery. Adv Drug Deliv Rev 56:581-587. https://doi.org/10.1016/j.addr.2003.10.023

18. Hashmi S, Ling P, Hashmi G et al (1995) Genetic transformation of nematodes using arrays of micromechanical piercing structures. Biotechniques 19:766-770

19. Stoeber B, Liepmann D (2000) Fluid injection through out-of-plane microneedles. IEEE, pp 224-228

20. Alva S (2008) FreeStyle lite-a blood glucose meter that requires no coding. J Diabetes Sci Technol 2:546-551. https://doi.org/10.1177/19322 9680800200402

21. Miller PR, Gittard SD, Edwards TL et al (2011) Integrated carbon fiber electrodes within hollow polymer microneedles for transdermal electrochemical sensing. Biomicrofluidics 5:013415. https://doi. org/10.1063/1.3569945

22. Gill HS, Prausnitz MR (2007) Coated microneedles for transdermal delivery. J Control Release 117:227-237. https://doi.org/10.1016/j.jconr el.2006.10.017

23. Caffarel-Salvador E, Brady AJ, Eltayib E et al (2015) Hydrogel-forming microneedle arrays allow detection of drugs and glucose in vivo: potential for use in diagnosis and therapeutic drug monitoring. PLOS ONE. https://doi.org/10.1371/journal.pone.0145644

24. Kommareddy S, Baudner BC, Oh S et al (2012) Dissolvable microneedle patches for the delivery of cell-culture-derived influenza vaccine antigens. J Pharm Sci 101:1021-1027. https://doi.org/10.1002/jps.23019

25. Liu L, Kai H, Nagamine K et al (2016) Porous polymer microneedles with interconnecting microchannels for rapid fluid transport. RSC Adv 6:48630-48635. https://doi.org/10.1039/C6RA07882F

26. Thomson RC, Yaszemski MJ, Powers JM, Mikos AG (1996) Fabrication of biodegradable polymer scaffolds to engineer trabecular bone. J Biomater Sci Polym Ed 7:23-38. https://doi.org/10.1163/156856295X00805 
27. Marin A, Andrianov AK (2011) Carboxymethylcellulose-Chitosan-coated microneedles with modulated hydration properties. J Appl Polym Sci 121:395-401. https://doi.org/10.1002/app.33608

28. Park Y-H, Ha SK, Choi l et al (2016) Fabrication of degradable carboxymethyl cellulose (CMC) microneedle with laser writing and replica molding process for enhancement of transdermal drug delivery. Biotechnol Bioproc E 21:110-118. https://doi.org/10.1007/s12257-015-0634-7

29. Lee JW, Park J-H, Prausnitz MR (2008) Dissolving microneedles for transdermal drug delivery. Biomaterials 29:2113-2124. https://doi. org/10.1016/j.biomaterials.2007.12.048

30. Demir YK, Akan Z, Kerimoglu O (2013) Sodium alginate microneedle arrays mediate the transdermal delivery of bovine serum albumin. PLoS ONE. https://doi.org/10.1371/journal.pone.0063819

31. Gill HS, Prausnitz MR (2007) Coating Formulations for Microneedles. Pharm Res 24:1369-1380. https://doi.org/10.1007/s11095-007-9286-4

32. Allou NB, Yadav A, Pal M, Goswamee RL (2018) Biocompatible nanocomposite of carboxymethyl cellulose and functionalized carbon-norfloxacin intercalated layered double hydroxides. Carbohyd Polym 186:282-289. https://doi.org/10.1016/j.carbpol.2018.01.066

33. Klöck G, Pfeffermann A, Ryser C et al (1997) Biocompatibility of mannuronic acid-rich alginates. Biomaterials 18:707-713. https://doi. org/10.1016/S0142-9612(96)00204-9

34. Kaderli S, Boulocher C, Pillet E et al (2015) A novel biocompatible hyaluronic acid-chitosan hybrid hydrogel for osteoarthrosis therapy. Int J Pharm 483:158-168. https://doi.org/10.1016/j.ijpharm.2015.01.052

35. Liu S, Jin M, Quan Y et al (2012) The development and characteristics of novel microneedle arrays fabricated from hyaluronic acid, and their application in the transdermal delivery of insulin. J Control Release 161:933-941. https://doi.org/10.1016/j.jconrel.2012.05.030

36. ASM International (1990) Metals handbooks, 10th edn. ASM International, USA
37. Gallagher AJ, Ni Anniadh A, Bruyere K et al (2012) Dynamic tensile properties of human skin. IRCOBI Conference 2012

38. Arora A, Hakim I, Baxter J et al (2007) Needle-free delivery of macromolecules across the skin by nanoliter-volume pulsed microjets. PNAS 104:4255-4260. https://doi.org/10.1073/pnas.0700182104

39. Zhou J, Ellis AV, Voelcker NH (2010) Recent developments in PDMS surface modification for microfluidic devices. Electrophoresis 31:2-16. https ://doi.org/10.1002/elps.200900475

40. Hatakeyama H, Hatakeyama T (1998) Interaction between water and hydrophilic polymers. Thermochim Acta 308:3-22. https://doi. org/10.1016/S0040-6031(97)00325-0

41. Gill HS, Denson DD, Burris BA, Prausnitz MR (2008) Effect of microneedle design on pain in human subjects. Clin J Pain 24:585-594. https://doi. org/10.1097/AJP.0b013e31816778f9

42. Fruhstorfer H, Müller T, Scheer E (1995) Capillary blood sampling: how much pain is necessary?. Part 2: Relation between penetration depth and puncture pain. Pract Diabetes Int 12:184-185. https://doi.org/10.1002/ pdi.1960120414

43. Winter WT, Smith PJC, Arnott S (1975) Hyaluronic acid: structure of a fully extended 3-fold helical sodium salt and comparison with the less extended 4-fold helical forms. J Mol Biol 99:219-235. https://doi. org/10.1016/S0022-2836(75)80142-2

44. Walker MP, Burckhard J, Mitts DA, Williams KB (2010) Dimensional change over time of extended-storage alginate impression materials. Angle Orthodontist 80:1110-1115. https://doi.org/10.2319/031510-150.1

\section{Publisher's Note}

Springer Nature remains neutral with regard to jurisdictional claims in published maps and institutional affiliations.

\section{Submit your manuscript to a SpringerOpen ${ }^{\circ}$ journal and benefit from:}

- Convenient online submission

- Rigorous peer review

- Open access: articles freely available online

- High visibility within the field

- Retaining the copyright to your article

Submit your next manuscript at springeropen.com 